\section{Open-access publishing can survive recession}

SIR - Your Commentaries on 'How to survive the recession' devote much discussion to the effects of the global recession on science (Nature 457, 957-963; 2009). However, the financial squeeze may also be affecting the publication output of research institutions in a more subtle way. It could be boosting the traditional reader-pays publication model for scientific journals at the expense of the author-pays, or openaccess, model.

Open-access journals ask authors to pay for processing their manuscripts (which involves organizing a form of quality control, formatting and distribution) so that the final product becomes freely available, and free to use if properly attributed. This model is widely believed to increase the visibility, dissemination and, eventually, the citation and impact of research findings. It is also praised for providing free access to muchneeded scientific literature in developing countries (see, for example, J. A. Evans and J. Reimer Science 323, 1025; 2009).

However, few peer-reviewed open-access journals have so far had a high impact factor in their field, except for a small number such as those published by the Public Library of Science and BioMed Central. They are therefore struggling to emerge and to attract the most prestigious research findings.

This situation could deteriorate further if open-access journals are forced to move to (partial) site licensing in order to cover their production costs - a shift recently undertaken by the Journal of Visualized Experiments (http://tinyurl.com/cmhuwk), for example - as authors become increasingly reluctant or unable to pay in the current financial climate.

Some publishers have adopted a scheme that allows authors to post their unformatted, accepted manuscripts on their institutional repositories, rendering conventional articles de facto open access without added cost. Encouraging authors to use this right would prevent further dampening of the move towards openly sharing scientific knowledge, to the benefit of all. Raf Aerts Division of Forest, Nature and Landscape, Katholieke Universiteit Leuven, Celestijnenlaan 200E-2411, 3001 Leuven, Belgium e-mail: raf.aerts@ees.kuleuven.be

\section{Crystal growers are being forced to scatter}

SIR - As you indicate in your News Feature 'China's crystal cache' (Nature 457, 953-955; 2009), China and Japan provide most new single crystals for research, and the supply in the United States and Europe is becoming more and more limited. One explanation for this decline is that researchers specializing in single-crystal growth are unable to find laboratories willing to support their work.

Very few places are still prepared to host the long-term, risky endeavours of crystal growers. Of the laboratories where I have worked and grown crystals over the past 30 years, not one is growing crystals today. I started out growing crystals in Poland, but left because, at that time, the country could not afford this expensive research. I quit my work at the University of Konstanz in Germany when the physics department discovered that it was cheaper to buy in crystals from abroad. Then, a few years ago, when I was at Bell Labs in the United States, work there switched from basic research to applications, and an initiative to support a crystal-growth laboratory was rejected by the US Department of Energy.

In the end, I came upon an enthusiasm for crystal growing at the Nanyang Technological
University in Singapore. I have set up a small laboratory at the School of Materials Science and Engineering where I can grow crystals, not necessarily those newly discovered materials that physicists wish to study, but those that I can afford at this time.

I do not lament. I belong to the lucky few who have been privileged to work with excellent physicists and to follow their passion for many years, crystallizing and exploring new materials.

Research administrators should grasp the need for longterm stability in laboratories where crystals are grown and the advantages of maintaining them inside large physics and materials departments and institutes. Crystal growers are still around, but they desperately need laboratories.

\section{Christian Kloc School of Materials \\ Science and Engineering, \\ Nanyang Technological University, Block N4.1, 50 Nanyang Avenue, Singapore 639798 \\ e-mail: ckloc@ntu.edu.sg}

\section{Struggle to translate Darwin's view of concurrency}

SIR - In your Editorial 'Humanity and evolution' (Nature 457, 763-764; 2009), you mention Charles Darwin's image of a fiercely competitive world. But did his view simply refer to the competition among organisms for limited resources?

It was Darwin's first translator, German palaeontologist Heinrich Georg Bronn, who interpreted Darwin's metaphorical 'struggle for existence' exclusively in these terms. Bronn transmuted this expression, which referred to the production of offspring by animals and plants, into Kampf ums Dasein ('fight for existence or life'). However, Darwin himself rejected this Malthusian translation.

In a letter to the physiologist Wilhelm T. Preyer on 29 March 1869, Darwin says: "I suspect that the German term, Kampf etc., does not give quite the same idea. The words 'struggle for existence' express, I think, exactly what 'concurrency' does. It is correct to say in English that two men struggle for existence, who may be hunting for the same food during a famine, and likewise when a single man is hunting for food; or again it may be said that a man struggles for existence against the waves of the sea when shipwrecked." (See E.-M. Engels Ann. Hist. Philos. Biol. 10, 31-54; 2005.)

But what does the word 'concurrency', Darwin's synonym for 'struggle for life', mean in this context? According to an English dictionary of 1893, concurrency had several meanings: pursuit of the same object with another, competition, rivalry; running together in place or time; accordance in operation or opinion, cooperation, consent. However, in modern English, concurrency, or 'concurrence' means simultaneous occurrence or coincidence, and agreement or cooperation. Hence, Darwin's term 'struggle for existence' (that is, concurrency) has two opposing meanings: competition and cooperation.

It follows that post-Darwinian discoveries, such as altruism in animal populations or mutualistic (symbiotic) interactions among organisms, cells or organelles - concepts integral to our modern theory of biological evolution - are not in conflict with Darwin's key term, which the philosopher Herbert Spencer later circumscribed as 'survival of the fittest'. If we equate fitness with lifetime reproductive success, the dual meaning of Darwin's word 'struggle', in the sense of concurrency, becomes immediately apparent.

\section{U. Kutschera Institute of Biology,} University of Kassel, Heinrich-PlettStrasse 40, 34109 Kassel, Germany e-mail: kut@uni-kassel.de

Science publishing issues are featured at Nautilus (http:// blogs.nature.com/nautilus). 